\title{
Comparative analysis of blind tropospheric correction models in Ghana
}

DOI: https://doi.org/10.1515/jogs-2020-0104

Received March 21, 2020; accepted February 10, 2021

Abstract: The impact of the earth's atmospheric layers, particularly the troposphere on Global Navigation satellite system (GNSS) signals has become a major concern in GNSS accurate positioning, navigation, surveillance and timing applications. For precise GNSS applications, tropospheric delay has to be mitigated as accurately as possible using tropospheric delay prediction models. However, the choice of a particular prediction model can significantly impair the positioning accuracy particularly when the model does not suit the user's environment. A performance assessment of these prediction models for a suitable one is very important. In this paper, an assessment study of the performances of five blind tropospheric delay prediction models, the UNB3m, EGNOS, GTrop, GPT2w and GPT3 models was conducted in Ghana over six selected Continuously Operating Reference Stations (CORS) using the $1^{\circ} \times 1^{\circ}$ gridded Vienna Mapping Function 3 (VMF3) zenith tropospheric delay (ZTD) product as a reference. The gridded VMF3-ZTD which is generated for every six hours on the $1^{\circ} \times 1^{\circ}$ grids was bilinearly interpolated both space and time and transferred from the grid heights to the respective heights of the CORS locations. The results show that the GPT3 model performed better in estimating the ZTD with an overall mean (bias: $2.05 \mathrm{~cm}$; RMS: $2.53 \mathrm{~cm}$ ), followed by GPT2w model (bias: $2.32 \mathrm{~cm}$; RMS: $2.76 \mathrm{~cm}$ ) and GTrop model (bias: $2.41 \mathrm{~cm} ; 2.82 \mathrm{~cm}$ ). UNB3m model (bias: $6.23 \mathrm{~cm}$; RMS: $6.43 \mathrm{~cm}$ ) and EGNOS model (bias: $6.70 \mathrm{~cm}$; RMS: $6.89 \mathrm{~cm}$ ) performed poorly. A multiple comparison test (MCT) was further performed on the RMSE of each model to check if there is significant difference at $5 \%$ significant level. The results show that the GPT3, GPT2w and GTrop models are significantly indifferent at 5\% significance level indicating that either of these models can be employed to mitigate the ZTD in the study

\footnotetext{
*Corresponding Author: S. Osah: Department of Geomatic Engineering, College of Engineering, Kwame Nkrumah University of Science and Technology, Kumasi, E-mail: osahsamuel@yahoo.ca A. A. Acheampong, C. Fosu, I. Dadzie: Department of Geomatic Engineering, College of Engineering, Kwame Nkrumah University of Science and Technology, Kumasi
}

area, nevertheless, the choice of GPT3 model will be more preferable.

Keywords: GNSS; Multiple Comparison Test; Prediction Models; Tropospheric Delay; Vienna Mapping Functions

\section{Introduction}

The advent of GNSS has not only revolutionized Positioning and Navigation, but Surveillance and Timing as well. Increased number of signals, more power on signals as well as enhanced algorithms have extended the functionality of GNSS into varied applications such as time transfer, GNSS Meteorology, remote sensing etc. (HofmannWellenhof et al., 2008; Leick et al., 2015; Xu and Xu, 2016). However, One of the key limitations that greatly affect precise and accurate solution when using GNSS technology is the problem of delays in signal propagation through the Earth's atmospheric layers, predominantly, the ionosphere and the troposphere (Yao and $\mathrm{Hu}, 2018$; Younes, 2017). GNSS signals propagating through the Earth's atmospheric layers, experience refraction due to the variations in refractivity $(\boldsymbol{N}>1)$ along the signal transmission path which changes the propagation speed and direction before arriving at the receiver, resulting in time delay and signal bending (Mendes, 1999; Sun et al., 2019). Consequently, these signal delays cause an increase in the optical path lengths travelled by the signals than the true geometric distances between the satellites in view and the receiver (Mendes, 1999; El-Rabbany, 2002). This induces an error in the position solution and eventually degrade the positioning accuracy (Ibrahim and El-Rabbany, 2011; Younes, 2017). The extent of the impact of ionospheric delay is usually in the range of $5 \mathrm{~m}$ to almost $15 \mathrm{~m}$ but can reach more than 100 or $150 \mathrm{~m}$ during severe geomagnetic storm and at lower elevation angles (El-Rabbany, 2002; Jin, 2004). Similarly, the impact of tropospheric delay ranges from about 2.0 to $2.6 \mathrm{~m}$ in the zenith direction to about 20 to $28 \mathrm{~m}$ near the horizon and at lower elevation angles (El-Rabbany, 2002; Sanlioglu and Zeybek, 2012). Thus, the impact of the atmosphere on GNSS signals has become one of the major accuracies limiting factors for GNSS applications and therefore, needs to be eliminated and/or mitigated for 
precise and accurate GNSS applications. Whereas ionospheric delay can to a large extent be removed from combinations of dual-frequency GNSS measurements owing to its dispersive nature, the tropospheric delays require modelling techniques for its mitigation (Yao et al., 2016).

Mendes (1999) proposed three basic techniques to correct tropospheric delays: pure modelling or model correction technique; direct calibration or conventional/traditional observing techniques such as radiosonde and water vapour radiometer (WVR) and Self-Calibration or parameter estimation technique. The pure modelling technique comprises two main categories (Hu and Yao, 2019; Sun et al., 2019). The first category is the traditional models which require real-time surface meteorological observations at the user's environment to predict the tropospheric delays. Examples include Hopfield model (Hopfield, 1969) and Saastamoinen model (Saastamoinen, 1972). The second category is the blind models which require user location and time information for the estimation of meteorological parameters extracted from climatological data or numeric weather prediction (NWP) models. The meteorological parameters are usually provided in a tabular form (look-up table values) or gridded form (grid-point values) with mean values, annual and semi-annual amplitude values and their seasonal variations. The estimated meteorological parameters are then used to compute the tropospheric delay at centimeter-level accuracy. Examples include UNB3m model (Leandro et al., 2008; Leandro et al., 2006), EGNOS model (Penna et al., 2001), GPT2w model (Böhm et al., 2015) and its updated version GPT3 (Landskron and Böhm, 2018).

The reliance of real-time surface meteorological data by the traditional models limits their real-time availability or usage for real-time navigation and positioning applications since real-time meteorological data is not easy to obtain (Liu et al., 2017). For this reason, the blind tropospheric models emerged to overcome such limitations. However, owing to the different variations of atmospheric constituents in a prevailing area as pertain to different climatic conditions, tropospheric effect on GNSS signals also differ, influencing the performance of these empirical prediction models (traditional and blind) at user locations (Liu et al., 2017; Tuka and El-Mowafy, 2013). Nevertheless, the hot conditions and thicker tropospheric layer (up to $16 \mathrm{~km}$ ) in relation to huge volumes and imbalance of water vapour content in the low-latitude or equatorial region makes the low-latitude region more susceptible to the impact of tropospheric delay (Musa et al., 2005) particularly Ghana, which is so close to the equator. It is therefore imperative to evaluate the impact of these blind tropospheric delay models in different places or regions for real-time positioning and navigational applications.

Owing to the varying performance of the prediction models over varying atmospheric conditions, a number of studies have been conducted to evaluate the performances of different blind tropospheric models. Zhang et al. (2016) evaluated three blind tropospheric delay models, IGGtrop, EGNOS, and UNB3m in China. With 5 years of GNSS derived ZTD from 25 stations of the Crustal Movement Observation Network of China (CMONOC), the study recommended the IGGtrop. Farah (2020) likewise evaluated the IGGtrop, EGNOS, and UNB3m models in the Northern hemisphere. Using the IGS-ZTDs as the benchmark, the UNB3m model was recommended the best choice for ZTD corrections, however, the IGGtrop model was as well recommended for use in this region. Chen et al. (2014) assessed the GPT2 tropospheric model and its application in precise point positioning (PPP) globally. Deo and ElMowafy (2019) also analysed the reduction of PPP convergence time in Australiathe using ZTDs obtained from GPT2, GPT2w, Numeric Weather Model (NWM) from the Australian Bureau of Meteorology (BoM), and European Centre for Medium-Range Weather Forcasts (ECMWF). Utilizing the IGS-ZTD product from four sites in Australia as reference, it was found that the BoM model has the best ZTD estimation. Chen et al. (2020) compared SHAtropE (Shanghai Astronomical observatory tropospheric delay model-Extented) model with GPT3 and UNB3m models in China. Employing data from 310 GNSS sites over 7 years, the result showed a superior performance of the SHAtropE model over the GPT3 and UNB3m models. Similarly, Xu et al. (2020) also compared the Wuhan-University Global Tropospheric Emperical Model (WGTEM) with the TropGrid2, ITG (Improved Tropospheric Grid), GPT2, and UNB3m models. Utilizing the ECMWF ERA-Interim data from 2001-2010 as reference, the results revealed that the WGTEM outperformed the other models. Isioye et al. (2015) assessed the performance of the GPT2w and UNB3m models in Africa using 1 year of IGS-ZTD product over 15 IGS stations in Africa. The study recommended the GPT2w model for use in correcting tropospheric delays for GNSS realtime positioning and navigation applications in Africa.

It is obvious from the above studies that, majority of the studies were conducted in the Asian region, particularly China, and not much study have been carried out in the low-latitude region,specifically Ghana. Moreover, all the studies were conducted using PPP approach and no study have utilized differential technique to assess the blind models. In addition, we are also of the view that data utilized in Isioye et al. (2015) didn't cover majority of West Africa where this study is conducted. As prior indi- 
cated, Ghana is situated near the equator, which offers interesting challenges with regards to the tropospheric delay (Abukari et al., 2019). Conducting this study in Ghana therefore offers the opportunity to assess these models under typical Ghana atmospheric condition (Zhang et al., 2016) thereby enhancing position accuracies especially now that Ghana has embarked on Nation-Wide GNSS CORS establishment.

This paper therefore compares the performance of five blind tropospheric delay models, GPT2w model, GPT3 model, GTrop model (Sun et al., 2019), UNB3m model and the EGNOS model in Ghana over six selected CORS using the $1^{\circ} \mathrm{x} 1^{\circ}$ gridded Vienna Mapping Function 3 (VMF3) ZTD product as a reference.

\section{Tropospheric Delay Models}

The troposphere forms the lower portion of the neutral atmosphere closest to the earth. It extends at a height of about $8 \mathrm{~km}$ over the poles and $16 \mathrm{~km}$ over the equator (Kos et al., 2009a; Misra and Enge, 2011). Delay caused by the troposphere stems from the sum of the propagation delay and signal bending which induces an excess propagation path length on the GNSS signals (Mendes, 1999). From Fermat's principle and following (Bevis et al., 1992; Mendes, 1999; Kleijer, 2004) the excess propagation path $\left(\Delta L_{r}^{t}\right)$ can be calculated by integration of the refractive index along the signal transmission path, $s$, from satellite, $t$ to receiver, $r$ at elevation angle $(\theta)$ via the troposphere as:

$$
\Delta L_{r}^{t}(\theta)=S-G=\underbrace{\int_{S}(n(s)-1) d s}_{\text {Pathdelay }}+\underbrace{\left[\int_{s} d s-\int_{G} d G\right]}_{\text {Signalbending }}
$$

where

$$
\begin{gathered}
S=\int_{r}^{t} c d t=\int_{r}^{t} \frac{c}{v} d s=\int_{S} n(s) d s \\
G=\int_{\text {vacuum }} d G=\int_{G} d G
\end{gathered}
$$

$S$ is the optical or electromagnetic path length [m], c = speed of light in vacuum $\left[\mathrm{ms}^{-1}\right], v=d s / d t$, the propagation speed through the troposphere $\left[\mathrm{ms}^{-1}\right], \mathrm{n}=c / v$, the refractive index, $G$ is the geometric range along the straight path between $t$ and $r$ assuming the signal travel through a vacuum.

In the zenith direction (ZD) where satellites are directly overhead the receiver (i.e. $\theta=90^{\circ}$ ), the signal path is a straight line (i.e. $\mathbf{S}$ and $G$ become identical) and the bending effect disappears with the assumption that the troposphere is horizontally stratified (Bevis et al., 1992; Mendes, 1999). Equation (1) now becomes:

$$
\Delta L=\int_{S}[n(s)-1] d s
$$

Expressing $n$ in terms of total refractivity $N$, where $N=$ $10^{-6}(n-1)$, Eq. (4) can be rewritten as:

$$
\Delta L=10^{-6} \int_{s} N(s) d s
$$

$N$ is a function of meteorological parameters such as pressure $[P(m b a r)]$, temperature $[(T(K)]$ and relative humidity $[R H(\%)]$ or water vapour partial pressure $[e$ (mbar)] along the signal transmission path and can be separated into hydrostatic or dry $\left(N_{d}\right)$ and wet $\left(N_{w}\right)$ components caused by dry gases (mainly $\mathrm{N}_{2}, \mathrm{O}_{2}$ ) and water vapour respectively (Sanz et al., 2013).

$$
N=N_{d}+N_{w}
$$

The refractivity $(N)$ can be related to the meteorological parameters $(P, T, e)$ as (Smith and Weintraub, 1953):

$$
N=\underbrace{\left[k_{1} \frac{P}{T}\right]}_{N_{d}}+\underbrace{\left[k_{2} \frac{e}{T}+k_{3} \frac{e}{T^{2}}\right]}_{N_{w}}
$$

$k_{1}, k_{2}, k_{3}$ are refractivity constants whose values according to Bevis et al (1994) are given as, $k_{2}=70.40 \pm$ $2.2 \mathrm{~K} / \mathrm{hpa}, \mathrm{k}_{3}=373900 \pm 1200 \mathrm{~K}^{2} / \mathrm{hpa}$.

Re-writing Eq. (5)

$$
\begin{aligned}
\Delta L= & 10^{-6} \int_{S}\left[N_{d}+N_{w}\right] d s \\
& =10^{-6} \int_{S} N_{d}(s) d s+10^{-6} \int_{S} N_{w}(s) d s
\end{aligned}
$$

Expressing Eq. (8) in terms of ZTD,

$$
Z T D=10^{-6} \int_{Z D} N_{d}(s) d s+10^{-6} \int_{Z D} N_{w}(s) d s
$$

Equation (9) can further be written as:

$$
Z T D=\underbrace{10^{-6} \int_{h}^{T O A} N_{d}(h) d h}_{Z H D}+\underbrace{10^{-6} \int_{h}^{T O A} N_{W}(h) d h}_{Z W D}
$$

where, $h$ is the height of station or receiver antenna, and TOA is the top of the atmosphere. It can be seen from Eqs. 
(8-10) that, ZTD is the sum of the Zenith Hydrostatic Delay (ZHD) and the Zenith Wet Delay (ZWD) expressed as:

$$
Z T D=Z H D+Z W D
$$

With an appropriate mapping function and using the satellite elevation angle $(\theta)$ as input, the ZTD can be resolved into the Slant Tropospheric Delay (STD) as:

$$
S T D=Z H D \times M F_{h}(\theta)+Z W D \times M F_{w}(\theta)
$$

where $M F_{h}$ and $M F_{w}$ represent the hydrostatic and wet mapping functions respectively.

The ZHD accounts for about $90 \%$ of the ZTD and can easily be modelled or predicted to sub-millimetre accuracy by empirical prediction models using surface meteorological observations whereas the ZWD accounts for the remaining $10 \%$ of the ZTD and in contrast to the ZHD, it cannot be precisely modelled or predicted due to its large spatial and temporal variability (Younes, 2016; Zhang et al., 2016). The troposphere is characterized as being a nondispersive medium for radio frequencies up to $15 \mathrm{GHz}$, hence its effect is independent of GNSS frequencies and therefore affects carrier phase and code measurements equally (Sanz et al., 2013).

\subsection{UNB3m and EGNOS Tropospheric Models}

The UNB3m and EGNOS models are based on the estimation of five meteorological parameters such as pressure $[P(m b a r)]$, temperature $[(T(K)]$, water vapour partial pressure $[e(m b a r)]$, temperature lapse rate $[\beta(K / m)]$ and water vapour pressure height factor $[(\lambda$ (dimensionless) $]$ derived from the U.S. Standard Atmosphere Supplements, 1966 using user location (latitude and height) and day of year (Leandro et al., 2008; Penna et al., 2001). The meteorological parameters are stored in a look-up table and account for the annual average and amplitude/seasonal variations. Tables can be found in (Leandro et al., 2008; Leandro et al., 2006; Penna et al., 2001).

The annual average and amplitude of each parameter $\left(P_{0}, T_{0}, R H_{0}, e_{0}, \beta_{0}\right.$ and $\left.\lambda_{0}\right)$ can be computed according to the following:

$$
\varepsilon_{\varphi}=\left\{\begin{array}{lr}
\varepsilon_{15}, & \text { if } \varphi \leq 15, \\
\varepsilon_{75}, & \text { if } \varphi \geq 75, \\
\varepsilon_{i}+\frac{\left(\varepsilon_{i+1}-\varepsilon_{i}\right)}{15} \cdot\left(\varphi-L a t_{i}\right), & \text { if } 15<\varphi<75
\end{array}\right.
$$

where $\varphi$ is the latitude of interest in degrees, $\varepsilon$ is the computed average or amplitude meteorological parameter, $i$ is the index of the nearest lower tabled latitude and Lat represents latitude from the look-up table. Each meteorological parameter value $(P, T, e, \beta, \lambda)$ can then be estimated for the desired day of year (doy) according to:

$$
X_{\phi, d o y}=A v g_{\phi}-A m p_{\phi} \cos \left(\left(\text { doy }-D_{\min }\right) \frac{2 \pi}{365.25}\right)
$$

where $X_{\phi, \text { doy }}$ represents the calculated parameter value for latitude $\phi$ and day of year (doy), $D_{\min }$ is 28 for northern latitudes and 211 for southern latitudes.

After the five meteorological parameters are computed, the zenith delays (ZHD and ZWD) are computed based on Saastamoinen model as:

$$
\begin{gathered}
Z H D=10^{-6} \cdot k_{1} \cdot \frac{R_{d} \cdot P}{g_{m}} \cdot\left(1-\frac{\beta \cdot H}{T}\right)^{\frac{g}{R_{d} \cdot \beta}} \\
Z W D=\frac{10^{-6} \cdot k \cdot R_{d}}{g_{m} \cdot(\lambda+1)-\alpha \cdot R_{d}} \cdot \frac{e}{T} \cdot\left(1-\frac{\beta \cdot H}{T}\right)^{\frac{(\lambda+1) g}{R_{d} \cdot \beta}-1}
\end{gathered}
$$

where

$k$ is an arbitrary constant for refractivity.

For UNB3m model, $k$ is computed from:

$$
k=T_{m} \cdot k_{2}^{\prime}+k_{3}
$$

$T_{m}$ is the mean temperature of water vapour in (kelvin) expressed as:

$$
T_{m}=T\left(1-\frac{\beta \cdot R_{d}}{g_{m} \cdot(\lambda+1)}\right)
$$

For the EGNOS model, $k=k_{2}$ with value 382000 .

$k_{1}, k_{2}$ and $k_{3}$ are refractivity constants with values $77.60 \mathrm{~K} / \mathrm{mbar}, 16.6 \mathrm{~K} / \mathrm{mbar}$ and $377600 \mathrm{~K}^{2} / \mathrm{mbar}$, respectively, $R_{d}$ is the specific gas constant of dry air (), $\mathrm{H}$ is the orthometric height in meters above sea level, $\mathrm{g}$ is the surface acceleration due to gravity $\left(9.80665 \mathrm{~ms}^{-2}\right), g_{m}$ is the gravity acceleration at the centroid of the atmospheric column above the GNSS antenna (in $\mathrm{ms}^{-2}$ ). For the EGNOS model, $g_{m}$ is set as constant $\left(9.784 \mathrm{~ms}^{-2}\right)$ whilst computed for the UNB3m model as:

$$
g_{m}=9 \cdot 784\left(1-0.00266 \cos 2 \phi-2.8 \times 10^{-7} H\right)
$$

For UNB3m model, relative humidity (RH) values are provided instead of $e$ values. $e$ values are computed from $\mathrm{RH}$ according to:

$$
e=\frac{R H}{100} \times e_{s} \times f_{w}
$$

$e_{s}$ is the saturation vapour pressure given by:

$$
\begin{aligned}
& e_{s}= \\
& 0.01 \times \exp \left(\begin{array}{l}
1.2378847 \times 10^{-5} T^{2}-1.9121316 \times 10^{-2} T \\
+33.93711047-6.3431645 \times 10^{3} T^{-1}
\end{array}\right)
\end{aligned}
$$


$f_{w}$ is the enhancement factor and can be determined by:

$$
f_{w}=1.00062+3.14 \times 10^{-6} P+5.6 \times 10^{-7}(T-273.15)^{2}
$$

The STD for both models is computed using Niell (1996) mapping function (NMF) for UNB3m model and Black and Eisner (1984) mapping function for EGNOS model. The Black and Eisner mapping function can be expressed as (Black and Eisner, 1984):

$M F(\theta)=\left[1-\left(\frac{\cos (\theta)}{1+0.001}\right)^{2}\right]^{-1 / 2}=\frac{1.001}{\sqrt{0.002001+\sin ^{2}(\theta)}}$

The NMF model can also be formulated following equations (24-27). The model is a function of station latitude $(\varphi)$ and observation time $t$ from January 0.0 (in UT days) and it is based on the interpolation of the average and seasonal amplitude values given in a tabular form at $15^{\circ}$ latitudinal interval. Table values can be found in (Niell, 1996). The general form of the model for both hydrostatic and wet mapping functions can be expressed as:

$$
m(\varepsilon)=\frac{1+\frac{a}{1+\frac{b}{1+c}}}{\sin (\varepsilon)+\frac{a}{\sin (\varepsilon)+\frac{b}{\sin (\varepsilon)+c}}}
$$

However, the addition of height correction term to the hydrostatic term differentiates the two models. Thus, the final hydrostatic mapping function $N M F_{h}$ is given as:

$$
N M F_{h}=m(\varepsilon)+H_{s} 10^{-3} M_{h}
$$

where

$$
M_{h}=\frac{1}{\sin (\varepsilon)} \frac{1+\frac{a_{h t}}{1+\frac{b_{h t}}{1+c h t}}}{\sin (\varepsilon)+\frac{a_{h t}}{\sin (\varepsilon)+\frac{b_{h t}}{\sin (\varepsilon)+c_{h t}}}}
$$

$H_{S}$ is the height of the station above sea level (km), $\epsilon$ is the elevation angle, a, b, and c are empirical coefficients with different values for the hydrostatic and wet terms. $a_{h t}, b_{h t}, c_{h t}$ are the coefficients in the height component. $\mathrm{a}, \mathrm{b}$, and c can be computed as follows:

$$
a(\varphi, t)=a_{a v g}(\varphi)+a_{a m p}(\varphi) \cos (2 \pi(t-28) / 365.25)
$$

where $t$ is the day of year (doy), $a_{a v g}, a_{a m p}$ are the average and seasonal amplitude values which can be obtained by the linear interpolation between the nearest $a(\varphi, t)$. The same procedure is applicable to $\mathrm{b}$ and $\mathrm{c}$.

\subsection{GPT2w and GPT3 Tropospheric Models}

GPT2w and GPT3 models provide internally the mean values plus annual and semi-annual amplitudes of various surface meteorological parameters such as pressure $[P(h p a)]$, temperature $\left[T\left({ }^{\circ} C\right)\right]$ and its lapse rate $\left[d T\left({ }^{\circ} \mathrm{C} / \mathrm{km}\right)\right]$, water vapour pressure $[e(\mathrm{hpa})]$ and its decrease factor $[\lambda$ (dimensionless)], weighted mean temperature $[\operatorname{Tm}(K)]$, as well as hydrostatic $\left(a_{h}\right)$ and wet $\left(a_{w}\right)$ mapping function coefficients of the VMF1 and VMF3 respectively. These parameters are based on the analysis of 37 monthly mean pressure level profiles of the European Centre for Medium-Range Weather Forecasts (ECMWF) ERAInterim reanalysis for a period of 10 years (2001-2010). Though both GPT2w and GPT3 models are the advanced versions of the GPT series, GPT3 is the most recent version and refinement of the GPT2w model. The models are both provided on a regular $1^{\circ} \times 1^{\circ}$ and $5^{\circ} \times 5^{\circ}$ global grids, however, this study utilized the $1^{\circ} \times 1^{\circ}$ resolution. Each meteorological parameter can be computed from equation (28) using the date of observation and station coordinates (latitude $(\varphi)$, longitude, ellipsoidal height $(h))$ as input:

$$
\begin{aligned}
r(t)= & A_{0}+A_{1} \cos \left(\frac{\text { doy }}{365.25} 2 \pi\right)+B_{1} \sin \left(\frac{\text { doy }}{365.25} 2 \pi\right) \\
& +A_{2} \cos \left(\frac{\text { doy }}{365.25} 4 \pi\right)+B_{2} \sin \left(\frac{\text { doy }}{365.25} 4 \pi\right)
\end{aligned}
$$

where, $A_{0}$ is the mean value, $\left(A_{1}, B_{1}\right)$ and $\left(A_{2}, B_{2}\right)$ are the annual and semi-annual amplitudes of the selected parameters $r$. The zenith delays ZHD and ZWD are computed based on Saastamoinen model as revised by Davis et al. (1985) and Askne and Nordius (1987) model respectively. They are formulated as:

$$
\begin{gathered}
Z H D=\frac{0.0022768 \cdot P}{1-0.00266 \cos (2 \varphi)-2.8 \times 10^{-7} \times h} \\
Z W D=10^{-6}\left[\left(k_{2}+\frac{k_{3}}{T_{m}}\right) \cdot \frac{R_{d} \cdot e}{g_{m} \cdot(\lambda+1)}\right]
\end{gathered}
$$

The GPT3 model provides tropospheric gradients (hydrostatic north and east gradients, wet north and east gradients) as additional outputs. The required slant delays are calculated using VMF1 for GPT2w model and VMF3 for GPT3 model.

The hydrostatic and wet VMF are computed as:

$$
M F_{h}(\epsilon)=\frac{1+\frac{a_{h}}{1+\frac{b_{h}}{1+c_{h}}}}{\sin (\epsilon)+\frac{a_{h}}{\sin (\epsilon)+\frac{b_{h}}{\sin (\epsilon)+c_{h}}}}
$$

$$
M F_{w}(\epsilon)=\frac{1+\frac{a_{w}}{1+\frac{b_{w}}{1+c_{w}}}}{\sin (\epsilon)+\frac{a_{w}}{\sin (\epsilon)+\frac{b_{w}}{\sin (\epsilon)+c_{w}}}}
$$

$a_{h}, b_{h}, c_{h}$ are hydrostatic mapping coefficients and $a_{w}, b_{w}, c_{w}$ are the wet mapping coefficients. $b_{h}, b_{w}, c_{h}$ 
and $c_{w}$ are determined through empirical means whereas $a_{h}$ and $a_{w}$ are determined from global analysis data of the ECMWF. The VMF1 and VMF3 data are available from the ECMWF provided daily at four epochs at 00:00, 06:00, 12:00 and 18:00 UT for a specific set of stations and on a global grid. Whereas VMF1 data is available on $2.0^{\circ} \times 2.5^{\circ}$ global grid, the VMF3 data is available on both $5^{\circ} \times 5^{\circ}$ and $1^{\circ} \times 1^{\circ}$ global grids. The VMF1 model coefficients $b_{h}, b_{w}$ and $c_{w}$ are assigned constant values as $b_{h}=0.0029$, $b_{w}=0.00146$ and $c_{w}=0.0391$ and while $c_{h}$ is given based on the doy and station latitude $(\varphi)$ as:

$$
\begin{aligned}
& c_{h}= \\
& {\left[\left(\cos \left(\frac{d o u-28}{365.25} \cdot 2 \pi+\Psi\right)+1\right) \cdot \frac{c_{11}}{2}+c_{10}\right] \cdot(1-\cos \varphi)}
\end{aligned}
$$

The parameters $c_{0}, c_{10}, c_{11}$ and $\Psi$ are provided in Table 1 below.

Table 1. Parameters for computing the hydrostatic mapping coefficient c

\begin{tabular}{lllll}
\hline Hemisphere & $c_{0}$ & $c_{10}$ & $c_{11}$ & $\Psi$ \\
\hline Northern & 0.062 & 0.001 & 0.005 & 0 \\
Southern & 0.062 & 0.002 & 0.007 & $\pi$ \\
\hline
\end{tabular}

Unlike the VMF1 model, the VMF3 model coefficients $b_{h}, b_{w}, c_{h}$ and $c_{w}$ are furnished with spatial and temporal variation components and are computed from equation (28). Where $r$ this time represents $b_{h}, b_{w}, c_{h}$ and $c_{w}$. The GPT2w and GPT3 models and their grid files can be downloaded from http://vmf.geo.tuwien.ac.at/codes/.

\subsection{Global Tropospheric (GTrop) Model}

GTrop model is a new tropospheric delay model providing globally mean values plus annual and semi-annual amplitudes of zenith tropospheric delays (ZHD and ZWD) with a spatial resolution of $1^{\circ} \times 1^{\circ}$. It is based on the analysis of 37 monthly pressure level profiles of the ECMWF ERAInterim reanalysis data from 1979 to 2017 . The model input requirements are the station latitude $(\varphi)$, longitude $(\lambda)$, ellipsoidal height $[\mathrm{h}(\mathrm{km})]$, year $(\mathrm{Y})$, and day of year (DOY). The delays (ZHD, ZWD) are computed by first finding the four grid points that are closest to the given location. The delays at these four points at the given height are then computed through Eq. (34). Finally, a bilinear interpolation is employed to interpolate the required delays at the given location. The GTrop model parameters (ZHD and
ZWD) are calculated as:

$$
\begin{gathered}
T D=\left[\begin{array}{c}
A_{1}+A_{2}(Y-1980)+A_{3} \cos \left(\frac{D O Y}{365.25} 2 \pi\right) \\
+A_{4} \sin \left(\frac{D O Y}{365.25} 2 \pi\right)+A_{5} \cos \left(\frac{D O Y}{365.25} 4 \pi\right) \\
+A_{6} \sin \left(\frac{D O Y}{365.25} 4 \pi\right)
\end{array}\right] \\
\left\{1-\left[\begin{array}{c}
A_{1}+A_{2}(Y-1980)+A_{3} \cos \left(\frac{D O Y}{365.25} 2 \pi\right) \\
+A_{4} \sin \left(\frac{D O Y}{365.25} 2 \pi\right)+A_{5} \cos \left(\frac{D O Y}{365.25} 4 \pi\right) \\
+A_{6} \sin \left(\frac{D O Y}{365.25} 4 \pi\right)
\end{array}\right]\left(h-h_{0}\right)\right.
\end{gathered}
$$

Where, $h_{0}$ is the height of the grid point in (km), $A_{i}$ and $B_{i}(i=1 \sim 12)$ are the model coefficients. The GTrop model is available at https://github.com/sun1753814280/GTrop.

The GTrop model provides only zenith tropospheric delays. To be able to provide the slant delays (SHD and SWD), the NMF model was employed.

\section{Materials and Methods}

\subsection{GNSS Data}

One month of GNSS data spanning from September 1 to September 30, 2019, were collected from six GNSS CORS located in four regions of Ghana, namely, Bolgatanga (Upper East region), Kumasi (Ashanti region), Accra (Greater Accra region), Takoradi and Tarkwa (Western region). Details of the stations and their visual locations are shown in Table 3 and Fig. 3 respectively. It is worth noting that the six CORS are the only available CORS so far in Ghana and their respective data at the period of this study, as these CORS are part of an ongoing CORS establishment project in Ghana by the Licensed Surveyors Association of Ghana (LISAG).

\subsection{VMF ZTD Data}

The Vienna Mapping Functions (VMF) formally the Global Geodetic Observing System (GGOS) atmosphere provides global gridded VMF1 and VMF3 zenith tropospheric products (http://vmf.geo.tuwien.ac.at/trop_products/GRID). They are generated from the European Centre for MediumRange Weather Forecasts (ECMWF) reanalysis data and are provided every 6 hours daily at four epochs 00, 06, 12 and 18 UTC. VMF3 is the successor of VMF1 realized on both $1^{\circ}$ and $5^{\circ}$ global grids (Landskron and Böhm, 2018) . The data fields of the gridded VMF-ZTD include ZHD, ZWD, and mapping function coefficients for both hydrostatic (ah) and wet (aw) components. ZTD is obtained by 
adding the ZHD and ZWD at the same point and time. This study utilized the $1^{\circ}$ grid resolution VMF3-ZTD products on all the four epochs during each day within the study period as reference for evaluating the prediction models ZTD estimates following (Sun et al., 2017; Yao et al., 2015; Yao et al., 2016) and also owing to the fact that the CORS employed in this study are not IGS. The precision and accuracy of the VMF-ZTDs have been investigated and validated against the IGS-ZTDs by (Yao et al., 2017, 2018) to be accurate enough for tropospheric delay mitigation and models evaluation.

\subsection{Data Processing}

(i) GNSS data processing - 24 hours GNSS data in rinex format collected from the six available CORS were processed at 60 -seconds sampling rate and $10^{\circ}$ elevation cutoff using goGPS software version 0.5 .2 beta1 (Realini and Reguzzoni, 2013; Herrera et al., 2016). The relative positioning technique on both code and carrier-phase doubledifference (DD) was utilized with Kalman filtering using the LISAG_SPINTEX station as the base and the remaining stations as rovers. In all, a total of five baselines were processed as shown in Table 2. The GNSS data were also processed in Precise Point Positioning (PPP) mode for the estimation of ZTD values using gLAB (Hernandez-Pajares et al., 2010) software. This was carried out with the intent of comparing the PPP ZTD values and those of the VMF3 in the study area.

(ii) Extraction of VMF3 ZTD - To derived the gridded VMF3-ZTD at the various CORS, the stations ellipsoidal coordinates (latitude, longitude, and height) and modified Julian (mjd) date obtained from the rinex observation data were used. The extractions were done using the MATLAB coded script or m-file 'SearchReadVMFgrids.m', which is a modified version of the file $\boldsymbol{v} \boldsymbol{m} \boldsymbol{f}$ __grid. $\boldsymbol{m}$ written by Landskron and Böhm (2018). For each epoch grid file (e.g. $00 \mathrm{UT}$ ), the routine first finds the coordinates of the four surrounding grid points that are closest to the specified locations of the CORS. A bilinear interpolation is then employed to interpolate the zenith delays at the heights of the grid points. By employing formulae suggested by Kouba (2008), the zenith delays at the grid heights are then transferred to the respective height of the locations of the COR stations using the orography file, orography_ell_1x1. To obtain the zenith delays for the current epoch, a linear interpolation using values from two surrounding epochs is employed.

It is worth mentioning that, the prediction models used in this study and other ancillary information relat- ing to the tropospheric delay modelling were all coded and implemented in the goGPS software. The final processed zenith tropospheric delays (ZTD) were extracted for analysis.

Table 2. Processed Baselines of the various CORS

\begin{tabular}{ccc}
\hline Baseline & Length $(\mathrm{km})$ & $\Delta \mathrm{H}(\mathrm{m})$ \\
\hline LSA_S - CREF & 580.33 & 167.107 \\
LSA_S - SGGA & 10.62 & 12.177 \\
LSA_S - LSA_A & 206.49 & 232.813 \\
LSA_S - LSA_TAD & 202.65 & -31.923 \\
LSA_S - LSA_TAR & 214.95 & 32.749 \\
\hline
\end{tabular}

\section{Results}

In order to analyze the performance of the EGNOS, UNB3m, GTrop, GPT2w and GPT3 models in the study area, the final ZTDs obtained from each of the prediction models were compared with the corresponding VMF3 ZTDs. The final coordinate solutions especially the vertical components were as well extracted and compared to the corresponding reference coordinates obtained from the CSRSPPP online positioning service. The mean Bias and Root Mean Square Error (RMSE) of each model were computed using equation (35) and a summary of the results are presented in Table 4 and Figs. 4 \& 5. Figure 4 also shows the models estimated ZTD at the various stations, while Figs. 7 \& 8 represent the mean baseline ZTD bias and mean baseline height difference (Bias) respectively.

To further investigate the performance of these models, a multiple comparison or Post Hoc test (MCT) with 'scheffe' technique (McHugh, 2011; Lee and Lee, 2018) was carried out to find out if the performances of the five (5) tropospheric delay models in relation to their RMSE values are significantly different from one another at 5\% significant level using Matlab. The multiple comparison test is used to determine which pairs of means are significantly different, and which pairs are not. The multiple comparison test provides an interactive graph with each group mean represented by a symbol (small circle) and a comparison interval or bar represented by a line extending out from the symbol as shown in Figs. 5 \& 6. Two groups (models) means are significantly different if their intervals are disjoint and they are not significantly different if their intervals overlap or intersect. For a selected group (e.g. GPT2w), the comparison interval is highlighted blue and all other groups that are significantly different are high- 
lighted red as shown in Fig. 5. The bars for the groups that are not significantly different are highlighted grey. A similar test was also carried out on VMF3 and PPP ZTD values and the result are presented in Fig. 6.

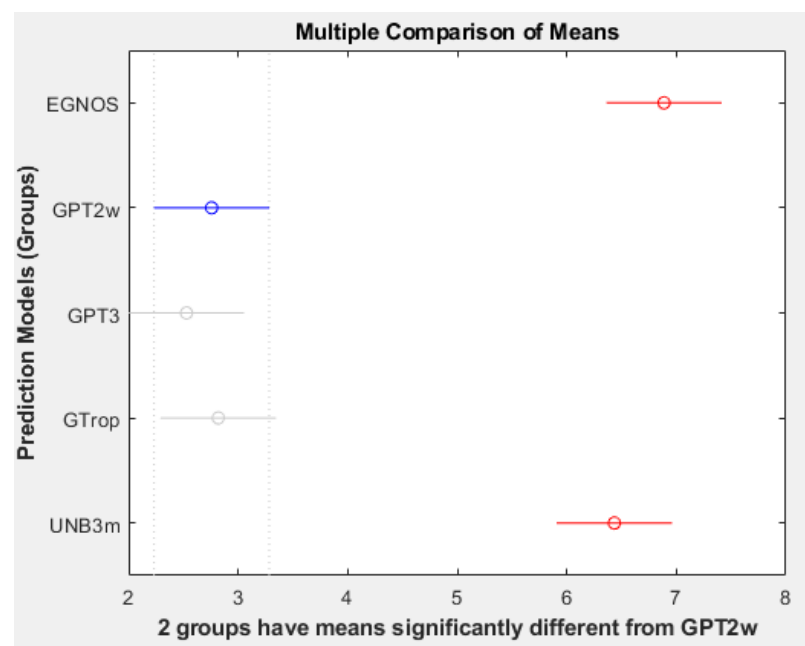

Fig. 1. Multiple Comparison of Group (Models) Means

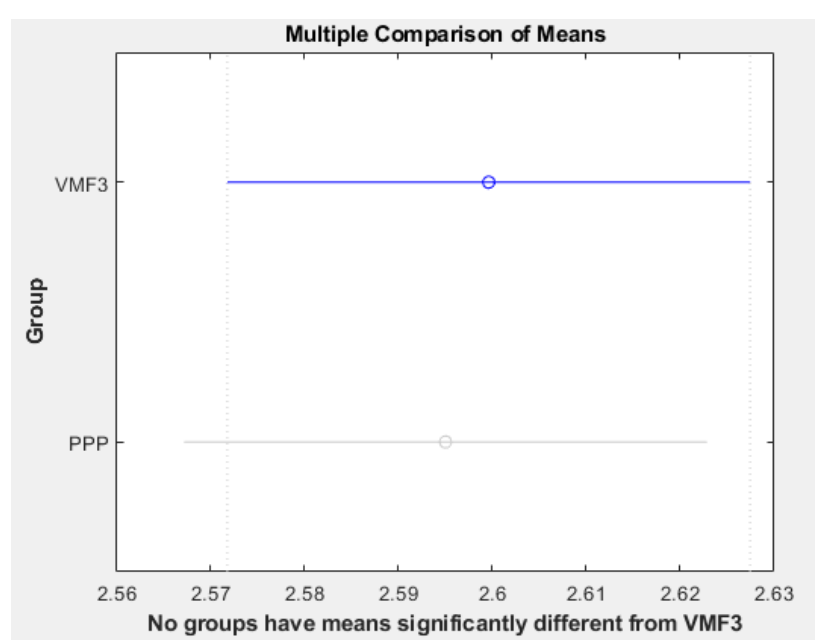

Fig. 2. Multiple Comparison of Group (VMF3, PPP) Means

$$
\left\{\begin{array}{c}
\text { Bias }=\frac{1}{N} \sum_{i=1}^{N}\left(Z T D_{i}^{M}-Z T D_{i}^{R}\right) \\
R M S E=\sqrt{\frac{1}{N} \sum_{i=1}^{N}\left(Z T D_{i}^{M}-0 Z T D_{i}^{R}\right)^{2}}
\end{array}\right.
$$

where $N$ is the number of observations, $Z T D_{i}^{M}$ and $Z T D_{i}^{R}$ are the estimated ZTD by the models and the reference respectively.

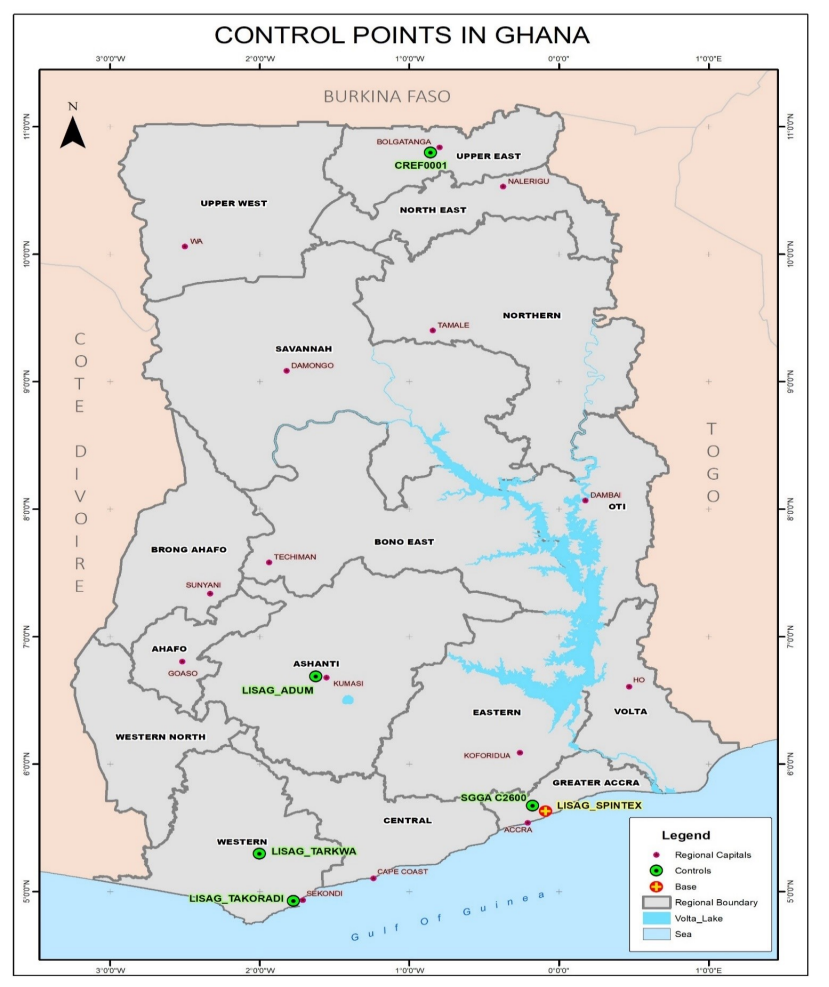

Fig. 3. Map of Ghana showing the Regions of GNSS CORS

\section{Discussion}

From the results in Table 3 and Figs. 3 and 4, the GPT3 model gave better results with smaller RMSE and bias values at all the stations except station CREF followed by the GPT2w model and then GTrop model. The UNB3m and EGNOS models performed poorly with high RMSE and bias values in all the stations as compared to the GPT3, GPT2w and GTrop models, however, the UNB3m model outperformed the EGNOS model. Since the UNB3m and EGNOS models employ the same values of meteorological parameter between $15^{\circ} \mathrm{S}$ and $15^{\circ} \mathrm{N}$, all reflect large bias and RMS in the study area (Yao et al., 2016a). The poor performance of the UNB3m model confirms the report by Huang et al. (2015) who assert that the UNB3m model performed poorly for mitigating ZTD in the low-latitude region. The performance of the GPT3 model over its predecessor GPT2w model also affirms the assertion by Landskron and Böhm ( 2018) that, the GPT3 model slightly surpass the GPT2w model in the . Moreover, it can also be deduced from the Figs. 2, 3, 4 \& 5 and Table 3 that, the GPT3, GPT2w and GTrop models produce comparable results as one group of models derived from the ECMWF ERA-Interim fields, while the UNB3m and EGNOS models likewise produce similar results as another group of models derived using the 
Table 3. GNSS stations in Ghana selected for this study

\begin{tabular}{|c|c|c|c|c|c|c|}
\hline Station & Code & City & Region & Latitude & Longitude & Height (m) \\
\hline CREF0001 & CREF & Bolgatanga & Upper East & $10^{\circ} 47^{\prime} 48.84^{\prime \prime}$ & $-0^{\circ} 51^{\prime} 25.55^{\prime \prime}$ & 242.690 \\
\hline LISAG_ADUM & LSA_A & Kumasi & Ashanti & $6^{\circ} 41^{\prime} 16.61^{\prime \prime}$ & $-1^{\circ} 37^{\prime} 30.81^{\prime \prime}$ & 308.396 \\
\hline LISAG_SPINTEX & LSA_S & Accra & Greater Accra & $5^{\circ} 38^{\prime} 1.27^{\prime \prime}$ & $-0^{\circ} 5^{\prime} 15.54^{\prime \prime}$ & 75.583 \\
\hline SGGA C2600 & SGGA & Accra & Greater Accra & $5^{\circ} 40^{\prime} 25.67^{\prime \prime}$ & $-0^{\circ} 10^{\prime} 29.15^{\prime \prime}$ & 87.761 \\
\hline LISAG_TAKORADI & LSA_TAD & Takoradi & Western & $4^{\circ} 55^{\prime} 31.75^{\prime \prime}$ & $-1^{\circ} 46 ’ 26.63^{\prime \prime}$ & 43.661 \\
\hline LISAG_TARKWA & LSA_TAR & Tarkwa & Western & $5^{\circ} 17^{\prime} 51.72^{\prime \prime}$ & $-2^{\circ} 0^{\prime} 0.15^{\prime \prime}$ & 108.333 \\
\hline
\end{tabular}

Table 4. Statistical results of the prediction models at the CORS (unit: $\mathrm{cm}$ )

\begin{tabular}{|c|c|c|c|c|c|c|c|c|c|c|}
\hline \multirow{2}{*}{ Model } & Bias & RMS & Bias & RMS & Bias & RMS & Bias & RMS & Bias & RMS \\
\hline & \multicolumn{2}{|c|}{ CREF } & \multicolumn{2}{|c|}{ SGGA } & \multicolumn{2}{|c|}{ LSA_A } & \multicolumn{2}{|c|}{ LSA_TAD } & \multicolumn{2}{|c|}{ LSA_TAR } \\
\hline EGNOS & 7.14 & 7.25 & 6.24 & 6.41 & 6.76 & 7.09 & 6.4 & 6.55 & 6.95 & 7.14 \\
\hline GPT2w & 3.23 & 3.68 & 1.58 & 2.01 & 2.21 & 2.62 & 2.14 & 2.59 & 2.46 & 2.89 \\
\hline GPT3 & 3.12 & 3.57 & 1.32 & 1.8 & 1.88 & 2.35 & 1.81 & 2.32 & 2.12 & 2.6 \\
\hline GTrop & 2.76 & 3.14 & 1.9 & 2.25 & 2.44 & 2.83 & 2.44 & 2.8 & 2.5 & 3.07 \\
\hline UNB3m & 6.66 & 6.78 & 5.76 & 5.95 & 6.31 & 6.63 & 5.92 & 6.09 & 6.48 & 6.72 \\
\hline
\end{tabular}

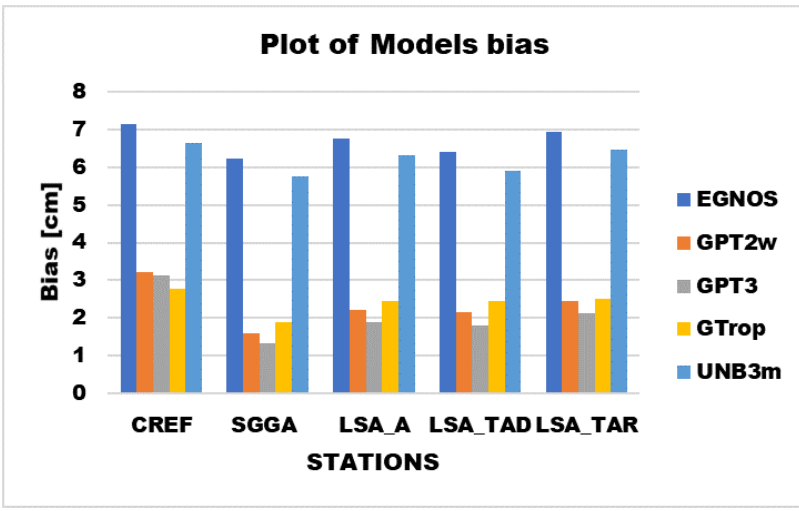

Fig. 4. Comparison of Bias of models at GNSS Stations (unit: $\mathrm{m}$ )

U.S. Standard Atmosphere Supplements data. It is clearly seen that the ECMWF derived models outperformed the U.S. Standard Atmosphere Supplements derived models in the study area due to the highly accurate and high spatial resolution $\left(1^{\circ}\right)$ meteorological data estimate from the ECMWF ERA-Interim fields compared to that of spatial resolution by the U.S. Standard Atmosphere Supplements derived models. Another reason could be that the ECMWF derived models consider both the annual and semi-annual variation, whilst the U.S. Standard Atmosphere Supplements derived models consider only the annual variation. Moreover, the difference in performance can also be associated with the modelling of the wet component of the tropospheric delay in the models (Hofmann-Wellenhof et al., 2008; Li et al., 2008). Water vapour is highly variable both in space and time. The low-latitude region, as prior indicated, is noted for having thicker tropospheric layer (up to 16km) (Misra and Enge, 2011), resulting in large vol-

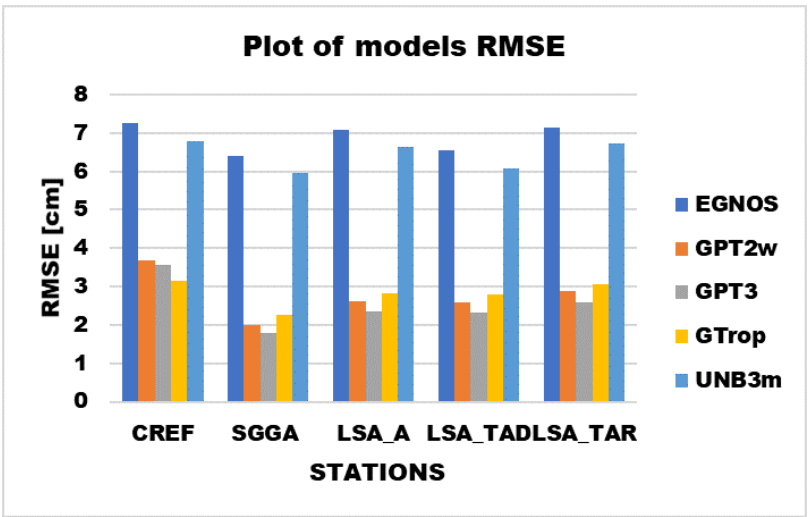

Fig. 5. Comparison of RMSE of models at GNSS Stations (unit: $\mathrm{m}$ )

umes and inhomogeneous of water vapour content (Amir and Musa, 2011). This lack of uniformity in the spatial and temporal distribution of water vapour can cause sudden changes in the water vapour in the atmosphere; making it difficult to model the ZWD (Yao et al., 2016b). A number of studies have reported the poor performance of the UNB3m and EGNOS models in the low-latitude region, which is correlated with large bias and RMS values (Liu et al., 2014; Huang et al., 2015; Chen et al., 2020). The large bias according to Yao et al. (2016a) is as a result of the abundance of water vapour, which changes rapidly in this region; increasing the difficulty of the ZWD modelling. In line with Kos et al. (2009b) the EGNOS or UNB3m model cannot account for tropospheric delay (ZWD) variations caused by the rapid weather changes over time, hence the large bias and RMS. Ghana, where this study is conducted, is located in the equatorial or low-latitude region on the west coast of Africa. The Greenwich meridian passes through east- 


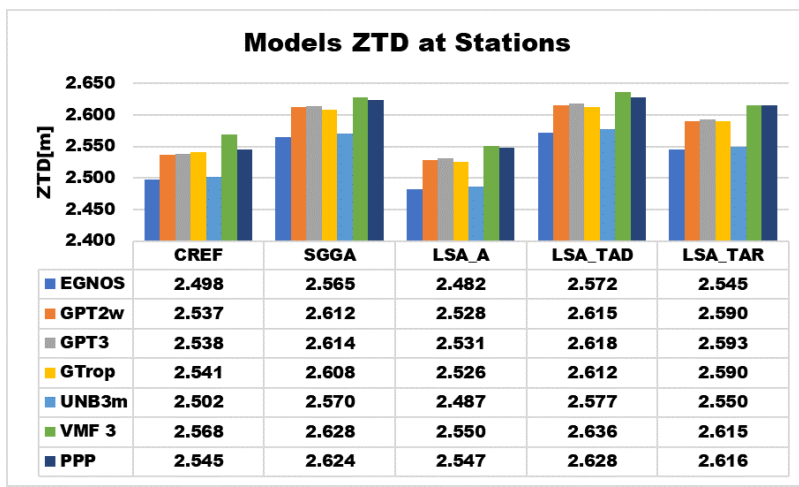

Fig. 6. Plot of estimated ZTD of models at GNSS Stations (unit: $\mathrm{m}$ )

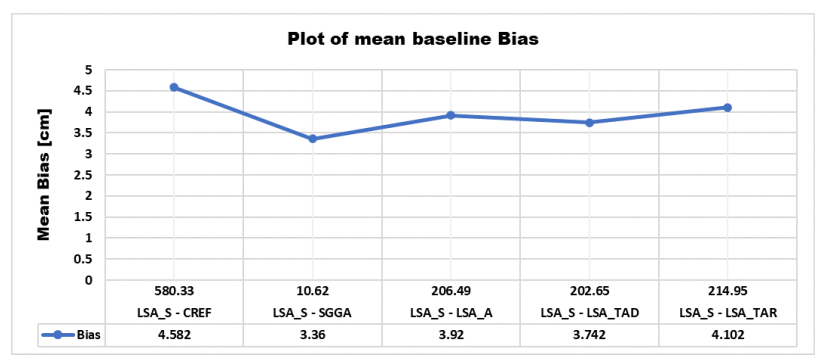

Fig. 7. Comparison of mean baseline ZTD bias

ern Ghana at Tema at longitude $0^{\circ}$ and latitude $5^{\circ}$ north of the Equator. Hence, Ghana is believed to be located close to the equator (Fosu et al., 2007; Poku-Gyamfi, 2009; Acheampong, 2015). Due to Ghana's proximity to the equator, it is more likely to experience severe turbulent and unstable atmospheric conditions (Poku-Gyamfi, 2009), making it susceptible to high tropospheric effect. Since the EGNOS or UNB3m model cannot account for changes in tropospheric delay due to Ghana's climate/troposphere, the biases and RMS are high in Ghana compared to the GPT2w, GPT3, and GTrop models, as shown in Table 4.

Furthermore, to investigate the impact of baselines length on tropospheric delays, comparison was made on the residuals between the various baselines as shown in Table 2. It is obvious from Fig. 7 that increase in baseline length between two stations increases the tropospheric error or bias. This is partly due to the fact that GNSS signals have to propagate through different amount of atmospheric constituent such as dry gases and water vapour within the troposphere owing to the difference in baseline length before arriving at the receivers on the ground (Yahya and Kamarudin, 2005). The longer the baseline length, the greater the different amount of the atmospheric contents the signals have propagate through, and the greater the effect of the tropospheric delay. The results in Fig. 7 affirms the assertion that tropospheric delay is a distant-dependent error (Yahya and Kamarudin,

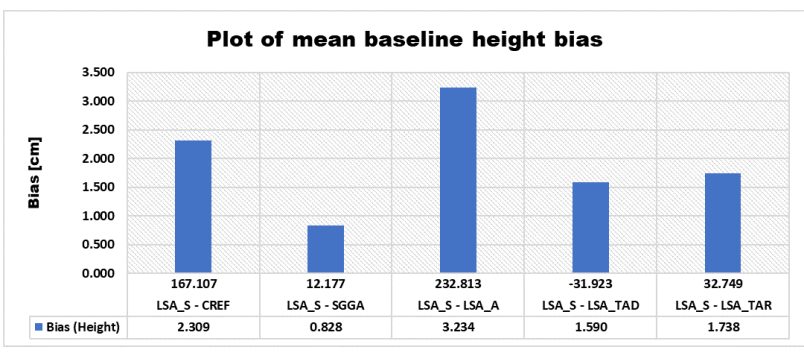

Fig. 8. Comparison of mean Baseline Height difference (Bias)

2005; Dodo et al., 2019). Additionally, the effect of baseline height difference $(\Delta \mathrm{H})$ on the tropospheric delay models was also analysed. Since the effect is seen more in the vertical component than the horizontal, the processed heights using the various prediction models were compared with the reference heights and the mean bias of all the models at each station or height differenced with respect to the base was computed as shown in Fig. 8. It is clearly seen in Fig. 8 that the tropospheric error in the height component increases with increasing baseline height difference $(\Delta \mathrm{H})$.

Once again, the result from the multiple comparison test as shown in Fig. 5 indicates that the mean of group 2 (GPT2w) in blue is considered to be significantly different from groups 1 (EGNOS) and 5 (UNB3m) in red with 95\% confidence level, but not significantly different from groups 3 (GPT3) and 4 (GTrop) shown in gray. Thus, the performance of the ECMWF derived models is significantly different from that of the U.S. Standard Atmosphere Supplements derived models at $95 \%$ confidence level in the study area.

Additionally, Fig. 4 above shows the mean ZTD of each tropospheric delay model estimated at each GNSS Station. The ZTD provides an insight into the tropospheric conditions over the GNSS station. It is obvious from Fig. 4 above that, the PPP ZTD values and those of the VMF3 are very comparable with an overall mean ZTD of (VMF3: $2.5996 \mathrm{~m}$; PPP: 2.5950 m). The MCT result in Fig. 6 further confirmed that the PPP ZTD values have means significantly indifferent from that of VMF3. The mean ZTD estimated at each station reveals that station LSA_TAD has the highest ZTD followed closely by station SGGA, LSA_TAR, then LSA_A and CREF. This result support the idea that stations at low latitude are highly liable to tropospheric delay (Musa et al., 2005; Dodo et al., 2019) and this is demonstrated in Fig. 9 below. 


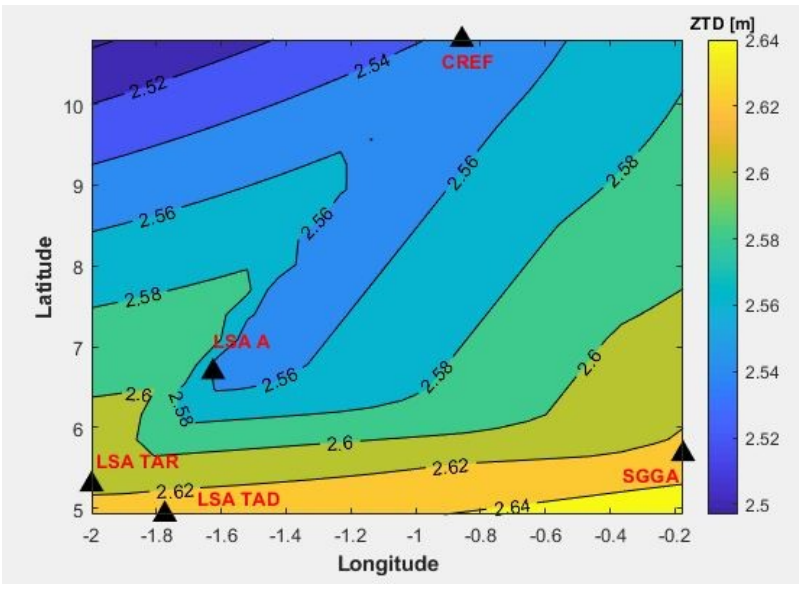

Fig. 9. Spatial distribution of the ZTD of the study area

\section{Conclusion}

In this paper, five blind tropospheric delay models were assessed using $1^{\circ} \times 1^{\circ}$ gridded VMF3 ZTD products as reference. The assessment was performed using six selected CORS over four regions of Ghana. Two distinct groups of blind tropospheric delay models have been investigated, the gridded ECMWF derived models (GPT3, GPT2w, GTrop) and the lookup table U.S. Standard Atmosphere Supplements derived models (UNB3m, EGNOS). The investigation revealed that the ECMWF derived models outperformed the U.S. Standard Atmosphere Supplements derived models in the study area. Moreover, the MCT further revealed that the performances of the ECMWF derived models are significantly different from that of the U.S. Standard Atmosphere Supplements derived models at 95\% confidence level.

Finally, it can be concluded that, for real-time GNSS positioning and navigational applications, either GPT3, GPT2w and GTrop models can perform well in correcting tropospheric delay in the study area, nevertheless, the choice of GPT3 model will be more optimum.

Acknowledgement: The authors wish to express their profound gratitude to Dr.-Ing Yaw Poku-Gyamfi from the office of the Licensed Surveyors Association of Ghana (LISAG) for providing the CORS data used in the study and also his valuable contributions and suggestions. More thanks also to Dr Quaye Ballard for his immense contributions and review.

\section{References}

Abukari, O. M., Acheampong, A. A. and Fosu, C., 2019, Analysis of GNSS Baseline Solutions in Ghana, South African J. Geomatics, 8(1), pp. 1-11.

Acheampong, A. A. (2015) Retrieval of Integrated Water Vapour from GNSS Signals for Numerical Weather Predictions. PhD Thesis, Department of Geomatics Engineering, Kwame Nkrumah University of science and Technology (KNUST), Ghana.

Amir, S. and Musa, T. A., 2011, GPS meteorology activities in the Malaysian Peninsula, in Proc. 10th Int. Symp. Exhibit. Geoinf.(ISG) ISPRS Commission.

Askne, J. and Nordius, H., 1987, Estimation of tropospheric delay for microwaves from surface weather data, Radio Sci.., 22(3), pp. 379-386.

Bevis, M., Businger, S., Chiswell, S., Herring, T. A., Anthes, R. A., Rocken, C. and Ware, R. H., 1994, GPS meteorology: Mapping zenith wet delays onto precipitable water, J. Appl. Meteorol., 33(3), pp. 379-386.

Bevis, M., Businger, S., Herring, T. A., Rocken, C., Anthes, R. A. and Ware, R. H., 1992, GPS meteorology: Remote sensing of atmospheric water vapor using the Global Positioning System, J. Geophys. Res. Atmos., 97(D14), pp. 15787-15801.

Black, H. D. and Eisner, A., 1984, Correcting satellite Doppler data for tropospheric effects, J. Geophys. Res. Atmos., 89(D2), pp. 2616-2626.

Böhm, J., Möller, G., Schindelegger, M., Pain, G. and Weber, R., 2015, Development of an improved empirical model for slant delays in the troposphere (GPT2w), GPS Solut., 19(3), pp. 433441.

Chen, J., Wang, J., Wang, A., Ding, J. and Zhang, Y., 2020, SHAtropE-A Regional Gridded ZTD Model for China and the Surrounding Areas, Remote Sens., 12(1), p. 165. doi: $10.3390 /$ rs12010165.

Chen, W., Gao, C. and Pan, S., 2014, Assessment of GPT2 empirical troposphere model and application analysis in precise point positioning, In: Sun J., Jiao W., Wu H., Lu M. (eds) China Satell. Navig. Conf. 2014 Proc.: Vol. II. Lect. Notes in Electrical Engineering, vol 304. Springer, Berlin, Heidelberg, pp. 451-463. doi: https://doi.org/10.1007/978-3-642-54743-0_37.

Davis, J. L., Herring, T. A., Shapiro, I. I., Rogers, A. E. E. and Elgered, G., 1985, Geodesy by radio interferometry: Effects of atmospheric modeling errors on estimates of baseline length, Radio sci., 20(6), pp. 1593-1607.

Deo, M. and El-Mowafy, A., 2019, Comparison of advanced troposphere models for aiding reduction of PPP convergence time in Australia, J. Spat. Sci., 64(3), pp. 381-403.

Dodo, J. D., Ekeanyanwu, U. O. and Ono, M. N., 2019, Evaluation of Five Tropospheric Delay Models on Global Navigation Satellite System Measurements in Southern Nigeria, J. Geosci., 7(4), pp. 201-211.

Dodo, J. D. and Idowu, T. O., 2010, Regional assessment of the GPS tropospheric delay models on the African GNSS network, J. Emerg. Trends Eng. Appl. Sci., 1(1), pp. 113-121.

El-Rabbany, A., 2002, Introduction to GPS: the global positioning system. First Edit. Artech house.

Farah, A., 2020, Assessment of BeiDou's Tropospheric Model (IGGtrop) for tropospheric delay correction in northern hemi- 
sphere, J. Appl. Geod., 14(1), pp. 29-38. doi: 10.1515/jag-20190015.

Fosu, C., Poku-Gyamfi, Y. and Hein, G. W., 2007, Global navigation satellite system (GNSS): a utility for sustainable development in Ghana, J. Sci. Technol., 27(2), pp. 132-140.

Hernandez-Pajares, M. et al., 2010, The ESA/UPC GNSS-Lab tool (gLAB): An advanced multipurpose package for GNSS data processing, in 2010 5th ESA Work. Satell. Navig. Technol. Eur. Work. GNSS Signals Signal Process, pp. 1-8. doi: 10.1109/NAVITEC.2010.5708032.

Herrera, A. M., Suhandri, H. F., Realini, E., Reguzzoni, M. and de Lacy, M. C., 2016, goGPS: open-source MATLAB software, GPS solut., 20(3), pp. 595-603. doi: 10.1007/s10291-015-0469-x.

van der Hoeven, A., Hanssen, R. F. and Ambrosius, B., 2002, Tropospheric Delay Estimation and Analysis Using GPS and SAR Interferometry, Phys. Chem. Earth, Parts $A / B / C$., 27(4-5), pp. 385-390.

Hofmann-Wellenhof, B., Lichtenegger, H. and Wasle, E., 2008, GNSS-global navigation satellite systems: GPS, GLONASS, Galileo, and more. Verlag Wien, New York: Springer.doi: 10.1007/978-3-211-73017-1

Hopfield, H. S., 1969, Two-quartic tropospheric refractivity profile for correcting satellite data, J. Geophys. Res., 74(18), pp. 44874499. doi: 10.1029/JC074i018p04487.

Hu, Y. and Yao, Y., 2019, ScienceDirect A new method for vertical stratification of zenith tropospheric delay, Adv. Sp. Res., 63(9), pp. 2857-2866. doi: 10.1016/j.asr.2018.10.035.

Huang, L., Xie, S., Liu, L., Feng, H. and Jiang, M., 2015, Assessment of zenith tropospheric delay derived from UNB3m model over Asia area, in Int. Conf. Intell. Earth Obs. Appl. 2015, p. 980835. doi: https://doi.org/10.1117/12.2207295.

Ibrahim, H. E. and El-Rabbany, A., 2011, Performance analysis of \{NOAA\} tropospheric signal delay model, Meas. Sci. Technol., 22(11), p. 115107. doi: 10.1088/0957-0233/22/11/115107.

Isioye, O. A., Combrinck, L. and Botai, J., 2015, Performance evaluation of Blind Tropospheric delay correction models over Africa, South African J. Geomatics. CONSAS, 4(4), pp. 502-525.

Jin, S., 2004, A Method To Establish GPS Grid Ionospheric Correct Model, Proc. Pan Ocean Remote Sens. Conf. (PORSEC), Nov. 29-Dec. 3, Concepcion, Chile, pp. 1-7.

Kleijer, F., 2004, Troposphere Modeling and Filtering for Precise GPS Leveling, PhD thesis, Technische Universiteit Delft, Netherlands.

Kos, T., Botinčan, M. and Dlesk, A., 2009a, Mitigating GNSS positioning errors due to atmospheric signal delays, J. Marit. Stud., 23(2), pp. 495-513.

Kos, T., Botincan, M. and Markezic, I., 2009b, Evaluation of EGNOS tropospheric delay model in South-Eastern Europe, J. Navig., 62(2), pp. 341-349. doi: 10.1017/S0373463308005146.

Kouba, J., 2008, Implementation and testing of the gridded Vienna Mapping Function 1 ( VMF1), J. Geod., 82(4-5), pp. 193-205. doi: 10.1007/s00190-007-0170-0.

Landskron, D. and Böhm, J., 2018, VMF3/GPT3: refined discrete and empirical troposphere mapping functions, J. Geod., 92(4), pp. 349-360. doi: 10.1007/s00190-017-1066-2.

Leandro, R. F., Langley, R. B. and Santos, M. C., 2008, UNB3m_pack: a neutral atmosphere delay package for radiometric space techniques, GPS solut., 12(1), pp. 65-70. doi: 10.1007/s10291007-0077-5.
Leandro, R., Santos, M. C. and Langley, R. B., 2006, UNB neutral atmosphere models: development and performance, in Proc. Inst. Navig. (ION), Natl. Tech. Meet. (NTM), 18-20 January, Monterrey, Calif., pp. 564-573.

Lee, S. and Lee, D. K., 2018, What is the proper way to apply the multiple comparison test?, Korean J. Anesthesiol., 71(5), pp. 353-360. doi: 10.4097/kja.d.18.00242.

Leick, A., Rapoport, L. and Tatarnikov, D., 2015, GPS satellite surveying. 4th ed., New York: John Wiley \& Sons, Inc., 807pp.

Li, Z. W., Ding, X. L., Chen, W., Liu, G. X., Shea, Y. K. and Emerson, N., 2008, Comparative study of empirical tropospheric models for the Hong Kong region, Surv. Rev., 40(310), pp. 328-341.

Liu, J., Chen, X., Sun, J. and Liu, Q., 2017, An analysis of GPT2/GPT2w+ Saastamoinen models for estimating zenith tropospheric delay over Asian area, Adv. Sp. Res., 59(3), pp. 824-832. doi: 10.1016/j.asr.2016.09.019.

Liu, L. L., Zhou, M., Zhang, T. X., Wang, W. and Huang, L. K., 2014, Assessment of EGNOS Model over Asia Area Using IGS_ZTD, in Appl. Mech. Mater., pp. 2182-2186. doi: https://doi.org/10.4028/www.scientific.net/AMM.501504.2182.

McHugh, M. L., 2011, Multiple comparison analysis testing in ANOVA, Biochem. medica Biochem. medica., 21(3), pp. 203209. doi: 10.11613/BM.2011.029.

Mendes, V. B., 1999, Modeling the neutral-atmospheric propagation delay in radiometric space techniques, UNB Geod. geomatics Eng. Tech. Rep. Department of Geodesy and Geomatics Engineering Technical Report No. 199, Univ. New Brunswick, Fredericton, New Brunswick, Canada, 353 pp.

Misra, P. and Enge, P., 2011, Global Positioning System: Signals, Measurements, and Performance, revised second ed. Lincoln, Massachusetts: Ganga-Jumana Press.

Musa, T. A., Lim, S. and Rizos, C., 2005, Low Latitude Troposphere: A Preliminary Study Using GPS CORS Data in South East Asia, Proc. ION 2005, Natl. Tech. Meet. United State Am.. Omnipress, USA, pp. 685-693.

Niell, A. E., 1996, Global mapping functions for the atmosphere delay at radio wavelengths, J. Geophys. Res. Solid Earth, 101(B2), pp. 3227-3246. doi: 10.1029/95JB03048.

Penna, N., Dodson, A. and Chen, W., 2001, Assessment of EGNOS tropospheric correction model, J. Navig., 54(1), pp. 37-55.

Poku-Gyamfi, Y., 2009, Establishment of GPS reference network in Ghana. PhD Thesis, Universitätsbibliothek der Universität der Bundeswehr München.

Realini, E. and Reguzzoni, M., 2013, goGPS: open source software for enhancing the accuracy of low-cost receivers by singlefrequency relative kinematic positioning, Meas. Sci. Technol., 24(11), p. 115010.

Saastamoinen, J., 1972, Atmospheric correction for the troposphere and stratosphere in radio ranging satellites, use Artif. Satell. Geod., pp. 247-251.

Sanlioglu, I. and Zeybek, M., 2012, Investigation On GPS Heighting Accuracy With Use Of Tropospheric Models In Commercial GPS Softwares For Different Heights, FIG Working Week 2012, (May 2012), pp. 6-10.

Sanz, J., Juan, J. M. and Hernández-Pajares, M., 2013, GNSS data processing, Vol. I: fundamentals and algorithms, Noordwijk, Netherlands ESA Commun. ESTEC TM-23/l.

Seeber, G., 2008, Satellite geodesy: foundations, methods, and applications. Walter de gruyter. 
Smith, E. K. and Weintraub, S., 1953, The constants in the equation for atmospheric refractive index at radio frequencies. in Proceedings of Proc. IRE 41'.

Sun, L., Chen, P., Wei, E. and Li, Q., 2017, Global model of zenith tropospheric delay proposed based on EOF analysis, $A d v . S p$. Res., 60(1), pp. 187-198. doi: 10.1016/j.asr.2017.03.045.

Sun, Z., Zhang, B. and Yao, Y., 2019, A Global Model for Estimating Tropospheric Delay and Weighted Mean Temperature Developed with Atmospheric Reanalysis Data from 1979 to 2017, Remote Sens., 11(16), p. 1893.

Tsui, J. B.-Y., 2005, Fundamentals of global positioning system receivers: a software approach. John Wiley \& Sons.

Tuka, A. and El-Mowafy, A., 2013, Performance evaluation of different troposphere delay models and mapping functions, Meas. J. Int. Meas. Confed., 46(2), pp. 928-937. doi: 10.1016/j.measurement.2012.10.015.

Xu, C., Yao, Y., Shi, J., Zhang, Q. and Peng, W., 2020, Development of Global Tropospheric Empirical Correction Model with High Temporal Resolution, Remote Sens., 12(4), p. 721. doi: $10.3390 / \mathrm{rs} 12040721$.

Xu, G. and Xu, Y., 2016, GPS: theory, algorithms and applications. Springer.

Yahya, M. H. and Kamarudin, M. N., 2005, The Impact of Tropospheric Delay Towards the Accuracy of GPS, Int. Symp. Exhib. Geoinformation, Penang, Malaysia, pp. 5-7.

Yahya, M. H. and Kamarudin, M. N., 2008, Analysis on the Residuals in GPS Measurement due to Tropospheric Effect at the Equatorial Region, in Int. Conf. Civ. Eng.

Yao, Y.-B., Zhang, B., Yan, F. and Xu, C.-Q., 2015, Two new sophisticated models for tropospheric delay corrections, Acta Geophys. Sin., 58(5), p. 82998113. doi: 10.6038/cjg20150503.

Yao, Y. and Hu, Y., 2018, An empirical zenith wet delay correction model using piecewise height functions, in Ann. Geophys., pp. 1507-1519.

Yao, Yibin, Hu, Y., Yu, C., Zhang, B. and Guo, J., 2016b, An improved global zenith tropospheric delay model GZTD2 considering diurnal variations, Nonlinear Process. Geophys., 23(3), pp. 127-136.

Yao, Y., Xu, X. and Hu, Y., 2017, Precision Analysis of GGOS Tropospheric Delay Product and Its Application in PPP, Acta Geod. Cartogr. Sin., 46(3), pp. 278-287. doi: https://doi.org/10.11947/j.AGCS.2017.20160383.

Yao, Y., Xu, X., Xu, C., Peng, W. and Wan, Y., 2018, GGOS tropospheric delay forecast product performance evaluation and its application in real-time PPP, J. Atmos. Solar-Terrestrial Phys., 175(2018), pp. 1-17. doi: 10.1016/j.jastp.2018.05.002.

Yao, YiBin, Zhang, B., Xu, C., He, C., Yu, C. and Yan, F., 2016a, A global empirical model for estimating zenith tropospheric delay, Sci. China Earth Sci., 59(1), pp. 118-128. doi: https://doi.org/10.1007/s11430-015-5173-8.

Younes, S. A.-M., 2016, Modeling investigation of wet tropospheric delay error and precipitable water vapor content in Egypt, Egypt. J. Remote Sens. Sp. Sci., 19(2), pp. 333-342. doi: 10.1016/j.ejrs.2016.05.002.

Younes, S. A.-M., 2017, Evaluation of Wet Mapping Functions Used in Modeling Tropospheric Propagation Delay Effect on GPS Measurements, Open Atmos. Sci. J., 11(1), pp. 1-15. doi: 10.2174/1874282301711010001.

Zhang, H., Yuan, Y., Li, W., Li, Y. and Chai, Y., 2016, Assessment of three tropospheric delay models (IGGtrop, EGNOS and UNB3m) based on precise point positioning in the Chinese region, Sensors, 16(1), p. 122. doi: 10.3390/s16010122. 